\title{
A construção da loucura no conto miopia progressiva
}

\author{
Joelma Correia da Silva (UNEAL) ${ }^{1}$ \\ ${ }^{1}$ Mestranda em Letras (UNEAL). E-mail: joelmaportugues1@gmail.com. \\ Ronaldo Gomes dos Santos (UNEAL) ${ }^{2}$ \\ Mestrando em Letras (UNEAL). E-mail: ronaldogomer123@gmail.com. \\ Amanda Ramalho de Freitas Brito (UNEAL/UFPB) ${ }^{3}$ \\ Doutora em Letras (UNEAL/UFPB). E-mail: amandaramalhobrito@gmail.com.
}

\begin{abstract}
Resumo - A discussão sobre a loucura assume ao longo da história do ocidente diferentes compreensões, passa da relação com a percepção de possessão demoníaca, seria para o homem um castigo divino advindo das consequências de manias pecaminosas, às persecutórias atuantes sobre pessoas que aparentemente mostrava um comportamento desviante das normas estabelecidas. No final do século XIX a Psicanálise apresenta novos modelos de entendimento da loucura sob a luz das três estruturas clínicas: neurose, psicose e perversão. Nesse sentido, a loucura torna-se então um reflexo da identidade individual de cada pessoa. Á luz das teorias sobre a loucura iremos mostrar uma concepção fundamentada em Lacan e Foucault. Partindo desses pressupostos podemos compreender a loucura como uma experiência sensível da humanidade, que busca se reconhecer nos sentidos criados por si e para o mundo a sua volta, causando assim, rupturas do real e imaginário. Para perceber essa experiência, usaremos as teorias de Lacan para analisar a categoria personagem no conto Miopia Progressiva, que está inserido no livro Felicidade Clandestina, de Clarice Lispector.
\end{abstract}

Palavras-chave: Loucura; Identificatória; Personagem-criança

\begin{abstract}
Abastract - The discussion of madness assumes throughout the history of the West different understandings, it goes from the relationship with the perception of demonic possession, it would be for man a divine punishment arising from the consequences of sinful manias, to persecutory acts on people who apparently showed deviant behavior established standards. At the end of the 19th century, Psychoanalysis presents new models of understanding madness in the light of the three clinical structures: neurosis, psychosis and perversion. In this sense, madness then becomes a reflection of each person's individual identity. In the light of theories about madness, we will show a conception based on Lacan and Foucault. Based on these assumptions, we can understand madness as a sensitive experience of humanity, which seeks to recognize itself in the senses created by itself and the world around it, thus causing ruptures of the real and the imaginary. To understand this experience, we will use Lacan's theories to analyze the character category in the short story Progressive Myopia, which is included in Clarice Lispector's book Clandestine Happiness.
\end{abstract}

\footnotetext{
${ }^{1}$ Mestranda em Letras (UNEAL). Contato: joelmaportugues1@ gmail.com.

${ }^{2}$ Mestrando em Letras (UNEAL). Contato: ronaldogomer123@gmail.com.

${ }^{3}$ Doutora em Letras (UNEAL/UFPB). Contato: amandaramalhobrito@gmail.com.
} 
Keywords: Madness; Identification; Child character

\section{Introdução}

Tendo como objetivo principal entender a maneira como o discurso literário se a própria da figura do louco no conto Miopia Progressiva. Nele, encontramos um tom levemente otimista, na medida em que aponta para alguma alternativa de reaproximação da autenticidade do sujeito pré-alienação. No conto em questão, o encontro do si mesmo com o mundo desejante familiar e a perda de contato com o si mesmo originário. Vemos um garoto que se esforça por predizer o movimento de seus familiares em sua direção, movimento esse que tem a atribuição de dizer quem ele é. "Num estado de permanente incerteza", continuamos a assistir o movimento alienante da constituição do eu, que se resume no paradoxo: cabe aos outros dizer o que eu sou. Ele nunca conseguia mapear o campo interpretativo familiar. Graças à instabilidade misteriosa dos outros de sua família, ele se desentendia deles e de si mesmo. Não sabia o que era.

Quando achava que tinha entendido o que nele provocava o movimento de admiração de sua família, marcado por pontuações exclamativas 'oh! que inteligente!', imitava a si mesmo, repetia seu gesto, numa tentativa de apoderar-se de si mesmo. Mas é repetidamente fracassado em suas tentativas de réplicas de si mesmo.

Para isso iremos tratar a questão da loucura no conto sob uma perspectiva crítica/discursiva. Esta perspectiva se debruça sobre os discursos de poder, retirando o foco do que seria a alienação mental apontar a loucura como experiência sensível de nova percepção sobre a realidade a partir do próprio símbolo da miopia.

A loucura passa ao longo dos tempos por algumas compreensões diferentes, passa da relação com a percepção de possessão demoníaca, pelo qual seria para o homem um castigo divino advindo das consequências de manias pecaminosas, para uma compreensão psíquica natural do homem, como sendo um fundamento da constituição humana. Dando-lhe um sentido próprio para vivência no mundo real emparelhada com a realidade a sua volta. A loucura torna-se então um reflexo da subjetividade de cada pessoa. 
A diversidade na forma de apresentação da temática dá-se pelo modo como a loucura, enquanto fenômeno humano tem sido conceituada e entendida em cada tempo e em cada contexto. Desde a Antiguidade clássica as noções de normalidade e anormalidade têm sofrido alterações e essas alterações serviram de base para expressões da loucura na Literatura.

$\mathrm{Na}$ era clássica greco-romana, a exclusão dos loucos, praticada socialmente, também foi praticada literariamente. Uma das poucas referências à loucura aparece no mito de Dionísio (Baco).

Foucault (2004, p.163) busca nos mostrar o que era a loucura para a Idade Clássica não como objeto natural do saber, mas enquanto estratégia que se operava sobre os corpos: "a loucura não pode ser encontrada no estado selvagem. A loucura só existe em uma sociedade, ela não existe fora das normas da sensibilidade que a isolam e das formas de repulsa que a excluem ou capturam.”.

A atenção dada ao louco durante a Idade Média foi baseada na noção de loucura da época que, vista como castigo de Deus ou uma forma de redenção, era explicada, inclusive, a partir do discurso religioso.

A loucura possui momentos distorcidos contrapondo a uma oposição das formas tidas como normais à vida cotidiana. Esse fato fortemente ressaltado pela crítica envolveu as discussões de autores como Michel Foucault (2004), já citado anteriormente, e Erving Goffman (2010) dispostos a observar a história e as práticas sociais vigentes.

A Loucura também pode ser vista como objeto historicamente constituído em Foucaut (2004), pois ao longo do livro, História da loucura, o autor deixa claro que a loucura não é um objeto natural, existente desde a aurora dos tempos e esperando para ser entendido pelo homem, mas uma criação do próprio homem. Não se "encontrou" um portador de distúrbios mentais e se o descobriu como tal, mas se criaram a loucura e o louco. Isso se deu a partir de tecnologias dos saberes sobre esse corpo específico, a partir de múltiplas transformações no modo de ver esse corpo desviante, como exemplificado a seguir:

Na Idade Média, e depois no Renascimento, a loucura está presente no horizonte social como um fato estético ou cotidiano; depois, no século XVII - a partir da internação - a loucura atravessa um período de silêncio, de exclusão. Ela perdeu essa função de manifestação, de revelação que ela tinha na época de Shakespeare e de Cervantes (FOUCAULT, 2004, p.163). 
Nessa passagem, mostra-se que, ao conceito de loucura, já existente enquanto experiências sensíveis da humanidade se foram subtraindo significações, numa construção daquilo que modernamente conhecemos como doença mental.

Foucault (2004), afirma também que a "loucura não poderia ser encontrada no estado selvagem, pois ela só existiria em uma sociedade, ela não existe fora das normas", essas normas seriam os principais motivos da exclusão, pois quando se foge do padrão preestabelecido pela sociedade recebe-se uma marca negativa. A loucura então é vista como sendo um instrumento de poder, pois é a partir do ideal que consiste na exaltação da razão, que o louco acaba se tornando um sinal contrário. Nestes meios, de modo que já não será tratado apenas como um mero erro, mas, também, como uma ameaça à razão e a todos que o cerca.

Para Lacan (1998, p. 173) a loucura seria o passo do "desenvolvimento dialético do ser humano", o louco seria então um formador de sentido.

Partindo desses pressupostos podemos compreender a loucura como uma experiência sensível da humanidade, que busca se reconhecer nos sentidos criados por si e para o mundo a sua volta. Causando rupturas entre o real e o imaginário.

\section{Tensões do delírio em Miopia Progressiva}

O conto Miopia Progressiva, alvo de nossa análise, está inserido no livro "Felicidade Clandestina", de 1971, da autora Clarice Lispector. Onde há uma caracterização da personagem-criança em busca de sua autoconfirmação.

Quando falamos do conto nos vem logo o pensamento das concepções da infância em Clarice Lispector, pois observamos os movimentos da criança no caminho da construção de sua subjetividade, a partir da relação com todos que o avaliam a todo o momento. Os esboços identitários que sustentam o menino estão em ambientes distintos, onde temos um processo alienante da inteligência que a personagem teria na construção do "eu", e que está num paradoxo, onde cabe ao outro dizer o que eu sou. 
Se era inteligente, não sabia. Ser ou não inteligente dependia da instabilidade dos outros. Às vezes o que ele dizia despertava de repente nos adultos um olhar satisfeito e astuto. (...) Assim, pois quando era inteligente, tinha ao mesmo tempo a inquieta sensação de inconsciência: alguma coisa lhe havia escapado. A chave de sua inteligência também lhe escapava. (LISPETOR, 1971).

Esse estado está relacionado como sendo normal, pois é a forma de autoconhecimento identitário da criança, que gera uma negação ou aceitação do "eu”. Portanto, o sujeito é formado no contato com os outros, que constitui uma dimensão eminentemente social. Uma tentativa de autoconstrução, ou seja, a construção de "si", e passa para uma compreensão psíquica natural do homem, como sendo um fundamento da constituição humana. Dando-lhe um sentido próprio para vivencia no mundo com sua realidade. A loucura torna-se então um reflexo da subjetividade de cada pessoa.

As categorias de identidade que formam a subjetividade são formadas através de práticas excludentes, que Foucault chama de práticas divisórias, que dividem o normal do anormal. Normal se refere à maioria ou ao grupo dominante, portanto, aqueles que se desviam desta norma são marginalizados. A personagem não é vista mais como inteligente por seus familiares porque seu conhecimento tornou-se comum, e isso o deixa a parte do meio.

\begin{abstract}
A marginalização tem efeitos em nível material, por exemplo, menos autoridade cultural para falar. As categorias normativas produzem efeitos psicológicos, tais como opressão internalizada ou baixa autoestima. Elas também têm efeitos materiais através de seu poder em definir e excluir. Por isso a identidade pode ser uma importante fonte de empoderamento. (MCLAREN, 2016,p.163)
\end{abstract}

A personagem (criança) é um sujeito social de momentos evolutivo e descentrado de um "eu". Verifica-se em suas ações ecos de diferentes aceitações sociais caracterizando uma heterogeneidade própria à sua constituição. Correlatos a essa heterogeneidade, contrastam o desejo, o poder e ao niilismo do sujeito ao considerar um nada.

Se era inteligente, não sabia. Ser ou não inteligente dependia da instabilidade dos outros. Às vezes o que ele dizia despertava de repente nos adultos um olhar satisfeito e astuto. (LISPETOR, 1971, 11).

Como nos afirma Foucault (2004, p. 275), “o sujeito não é uma substância. É uma forma, e essa forma nem sempre é, sobretudo, idêntica a si mesma. [...] Há, indubitavelmente, relações e interferências entre essas diferentes formas do sujeito. Em cada caso, se exercem, 
se estabelecem consigo formas de relação diferentes entre o sujeito e o meio. E o que me interessa é, precisamente, a constituição histórica dessas diferentes formas do sujeito. ’

O personagem do conto não sabia o que era, pois sua família o fazia duvidar de sua suposta inteligência. As tentativas de se mostrar inteligente estava se desvaindo, e agora ficava uma crise que o perturbava. Pois a inteligência não era dele, e sim da intenção dos outros, e de achá-lo inteligente. Dependia sempre de juízos de comparação. O valor atribuído a essa inteligência é sempre fálico, na medida em que o falo Deve ser entendido como a voz cêntrica de uma autoridade constituída sobre o corpo do outro. O imaginário comporta então que todos se situem enquanto objetos comparáveis uns com os outros, distribuíveis segundo uma escala.

Nestas situações desvendaremos a atuação e de como a loucura se instaura na autoconstrução dos sentimentos e encontros da personagem.

\begin{abstract}
Assim, pois, quando era considerado inteligente, tinha ao mesmo tempo a inquieta sensação de inconsciência: alguma coisa lhe havia escapado. A chave de sua inteligência também lhe escapava. Pois às vezes, procurando imitar a si mesmo, dizia coisas que iriam certamente provocar de novo o rápido movimento no tabuleiro de damas, pois era esta a impressão de mecanismo automático que ele tinha dos membros de sua família: ao dizer alguma coisa inteligente, cada adulto olharia rapidamente o outro, com um sorriso claramente suprimido dos lábios, um sorriso apenas indicado com os olhos, "como nós sorriríamos agora, se não fôssemos bons educadores" - e, como numa quadrilha de dança de filme de faroeste, cada um teria de algum modo trocado de par e lugar. (LISPETOR, 1971, 11).
\end{abstract}

Essas situações são então caracterizadas como um Assujeitamento Ideológico, pois ele não conseguia mapear o campo interpretativo familiar, o que Brandão (2004, p. 105) define como algo que consiste em fazer com que cada indivíduo (sem que ele torne consciência disso, mas, ao contrário, tenha a impressão de que é senhor de sua própria vontade) seja levado a ocupar um lugar, mesmo que não seja seu, a identificar-se ideologicamente como grupos ou classes de uma determinada formação social. No caso do conto isto se da quando a admiração a suposta inteligência da criança é questionada por ele mesmo.

Essa presença da Personagem-criança que ainda não descobriu a chave de sua inteligência devido à instabilidade dos outros à sua volta é uma singularidade do conto. Pois quando ele faz uma observação que é considerada inteligente, ao repeti-la em outro momento, ele espera que ela acarrete uma reação parecida, porém o ato não se repete. $O$ que é considerado inteligente um dia, já não é mais em outro. 
É então que surge sua miopia e progride, pois agora tudo havia perdido o sentido, e ele mesmo tinha perdido o foco das coisas. O próprio garoto cria instabilidades nos outros ao criar perspectivas instáveis de ralação do "eu" com o "outro". Essas tensões geram o delírio no menino, tornando-se então um reflexo de sua subjetividade, como consequência da busca pelo autoconhecimento.

\footnotetext{
Um pouco nervoso, diziam (...). Mas "nervoso" era o nome que a família estava dando à instabilidade de julgamento da própria família. Outro nome que a instabilidade dos adultos lhe dava era o de "bem comportado", "dócil". Dando assim um nome não ao que ele era, mas à necessidade variável dos momentos. (LISPETOR, 1971, 12).
}

Quando lhe disseram que iria passar um dia com uma prima sem filhos, ele colocou-se a planejar o dia da visita. Criando assim muita expectativa. Porém ele não contava com um dente de ouro na boca de sua prima, o que o faz ficar desequilibrado, criando mais tensões que acabam descontruindo toda construção antecipada por sua mente.

Diante da instabilidade da aceitação de sua prima, o menino tem então um momento de lucidez, e é partir desse momento epifânico que ele consegue perceber o mundo com clareza, que o faz aceitar as relações de extremo impossível.

Mediante essa atenção com liberdade, sustentado por esse horizonte amoroso não invasivo que a prima lhe oferece, dá-se "o relance mais profundo e simples que teve da espécie de universo em que vivia e onde viveria", o menino pela primeira vez vê "claramente o mundo". "Foi apenas como se ele tivesse tirado os óculos, e a miopia mesmo é que o fizesse enxergar", “com a fixidez reverberada de cego". A visibilidade última estaria na não nitidez, no embaçamento míope, na cegueira, naquilo que não tem contornos, que não se desenha.

O menino então decide aceitar a (loucura) instabilidade das coisas e o fato de que nunca encontrará a chave da inteligência, pois não dependia do outro, e sim de sua aceitação. O menino aprecia "sua" inteligência e descobre-se, e tem uma progressão ao autoconhecimento. No entanto, não podemos negar a intencionalidade (marcas do inconsciente, voz do outro), desconstruída diante do momento epifânico.

O conto se encerra com uma compreensão de que, não importa o quanto tentemos manipular ou controlar nossas vidas, não há nada que possamos fazer em relação aos aspectos 
representativos da loucura, apenas podemos investir nela como uma possibilidade de reestabelecimento desse "eu", estando ela atrelada a um processo de construção da voz do sujeito na relação estabelecida com a família e com a sociedade, reflexo de uma privação e de opressão mental, que ocasiona uma ação identificatória.

Vemos o garoto como um ser bastante desconfiado dos feedbacks que seu entorno lhe oferecia. As lentes de seus óculos encarnam sua vontade de atribuir figurabilidade estáveis aos outros e, por conseguinte a si mesmo.

É a partir desta análise que podemos perceber que pode haver a possibilidade de um diálogo entre o louco e o "são", em que não haveria interdições na linguagem do louco. Levando o estudo sobre a loucura para um campo mais extenso.

\section{Conclusão}

Diante do exposto acima, pode-se dizer que os encontros entre loucura e Literatura ocorreram em função de contextos em que a loucura foi de alguma forma questionada, no sentido de se querer saber mais sobre ela. Vista como algo reconhecível e ao mesmo tempo misterioso ao olhar da pessoa denominada louca e por isso incapaz de falar por si apresentando argumentos e sentidos que de fato a caracterize com sua subjetividade.

A mudança de foco, do louco ou da loucura, para aquele que o identifica e determina, proporciona ao leitor enxergar a loucura por outro ângulo e assim entender como os discursos são produzidos, como são revestidos de verdade e o real sentido produzido para melhor sustentar o aparente status natural de convicções e opiniões inalteráveis. Esse é o ponto de tensão da obra, uma vez que, a personagem não se reconhece porque o delírio é a construção crítica da realidade

A Literatura como manifestação artística rompe com os dogmas que a sociedade lhe impõe. Ao tematizar sobre os fatos humanos, sociais e históricos, ela busca conferir um trato estético e verossímil para experimentação do mundo. Assim, quando o texto literário se debruça sobre uma caricatura procura fazer dela loucura, não visando riso ou deboche, mas procurando, a partir desta caricatura, fazer da loucura uma dúvida, para então fazer dela 
crítica e reflexão. Já que a loucura possui seu translado como uma oposição às formas ditas normais da vida cotidiana.

\section{Referências}

BRANDÃO, Helena Hathsue Nagamine. Introdução a analise do discurso. $2^{\mathrm{a}}$ ed. São Paulo: Editora UNICAM, 2004.

FOUCAULT, Michel. História da loucura. São Paulo: Perspectiva, 2004.

FOUCAULT, Michel. A Ética do Cuidado de Si como Prática da Liberdade. In: MOTTA, Manoel Barros da. Ditos \&Escritos V-Michel Foucault: Ética, Sexualidade, Política. Tradução de Elisa Monteiro e Inês Autran Dourado Barbosa. Rio de Janeiro: Forense Universitária, 2004. p. 264-287.

GOFFMAN, Erving. Manicômios, Prisões e Conventos. São Paulo: Perspectiva, 2010.

LACAN, Jacques (1946) Formulações sobre a causalidade psíquica. In: _. Escritos. Rio de Janeiro: Jorge Zahar, 1998.

LISPETOR, Clarice. Felicidade Clandestina. Rio de Janeiro: 1ª ed. Rocco. 1971.

MCLAREN, Margaret A. .Foucault, feminismo e subjetividade. São Paulo: Intermeios, 2016. 